\title{
LA INTERFAZ INDÍGENA-COLONIAL Y LA MIGRACIÓN DE IMAGINARIOS: EL CASO DE TUPÍ Y GUARANÍ
}

\section{THE NATIVE-COLONIAL INTERFACE AND THE MIGRATION OF IMAGINARIES: THE CASE OF TUPÍ AND GUARANÍ}

\author{
Dra. Eugenia Ortiz Gambetta \\ CONICET-Universidad Nacional de La Plata, Argentina \\ eortiz@fahce.unlp.edu.ar
}

\begin{abstract}
Resumen:
Este artículo busca indagar en la conformación de una leyenda literaria guaraní, la de los hermanos Tupí y Guaraní, y analizarla desde el concepto "interfaz indígena-colonial”. El objetivo principal es analizar este tipo de discurso en tres dimensiones espaciales: como cartografía de los desplazamientos, como la intersección de realidades culturales, y por último, desde la lógica de proyección «providencialista» de la conquista, como forma de validación histórico-teológica y política.
\end{abstract}

Palabras clave: Leyendas guaraníes, Tupí y Guaraní, interfaz indígena-colonial, discursos coloniales.

\begin{abstract}
:
This paper aims to consider the conformation of a Guarani folk tales, that of the Tupi and Guarani brothers, and analyze it from the concept "native-colonial interface". The main objective is to analyze this type of discourse in three spatial dimensions: as a cartography of displacements, as the intersection of cultural realities, and finally, from the logic of "providentialist" projection of conquest, as a form of historical-theological validation and politics.
\end{abstract}

Keywords: Guarani legends, Tupí and Guaraní, native-colonial interface, colonial discourses.

Enviado: 10 de mayo de 2019

Aceptado: 30 de junio de 2019

\section{La interfaz cultural indígena-colonial}

Los estudios latinoamericanos en general han tenido una rotunda maduración durante la segunda mitad del siglo XX y comienzos del XXI en cuanto a las interacciones indígenoeuropeas durante la colonia. Desde la visión de los vencidos (León Portilla; Wachtel; Garibay) hasta la crítica poscolonial y decolonial (de Toro; de Toro y de Toro; 
Mignolo1995, 2011; Castro Klarén) se han estudiado representaciones de la interacción entre los colectivos, se han ido sumando matices y testimonios a esa dinámica. También se han ampliado los trabajos que dan cuenta de la interculturalidad presente en el esquema de dominación española sobre el territorio de América del Sur (Leinhard; Gruzinski). En este ámbito, cuestiones como la cultura oral y la excesiva escrituralidad del período colonial (Oesterreicher), las dinámicas de las culturas no tipográficas frente a la hegemonía de lo escrito (Boone y Mignolo) se insertan en temas de violencia simbólica pero también en productos culturales significativos, desde las primeras gramáticas de lenguas indígenas hasta las crónicas mestizas.

Existen muchos ejemplos de migración de imaginarios y transvases que se produjeron en diversas interfaces culturales en América Latina, desde la conquista hasta nuestros días. En este trabajo, considerar el concepto de "interfaz cultural” servirá como un orientador para el análisis de la reconstrucción de la mitología tupí-guaraní en el entorno del Río de la Plata. Específicamente, tomaré el caso de la emergencia de la leyenda de los hermanos Tupí y Guaraní que aparece en diversos textos coloniales y en los repertorios de leyendas literarias; de esta manera, aquí no me centraré en el relato de insumo de etnógrafos y antropólogos, sino en el subgénero literario o tradición discursiva presente en los soportes de difusión del tema, educativos, folclóricos y literarios.

La construcción de la leyenda de los hermanos Tupí y Guaraní, un mito de origen y población, es un caso paradigmático para seguir esa discontinuidad de la transmisión y circulación de leyendas en el ámbito de la literatura. La propuesta es relacionarla con el concepto "interfaz cultural" para considerar el entramado narrativo del relato en tres dimensiones espaciales: la leyenda como cartografía de los desplazamientos, como la intersección de realidades culturales, y por último, desde la lógica de proyección providencialista de la conquista, como forma de validación política, pero sobre todo, histórico-teológica.

En relación al concepto "interfaz cultural", sigo los trabajos de Martin Nakata (1997; 2010). Si una interfaz es una zona de comunicación o acción de un sistema sobre otro, en el mundo digital y en el físico, Nakata toma el término para conceptualizar la zona de interacción de dos culturas y las formas de conocimiento que entran en juego, la tensión entre las "visiones del mundo" de las colectividades (Nakata 2010: 15). La interfaz también 
puede asociarse con el concepto "zona de contacto" que Pratt (33-40) lleva a los estudios culturales desde la sociolingüística, y en gran medida, al resultado de ésta,la transculturación, que de Ortiz en adelante los estudios latinoamericanos han sabido sacar provecho. Incluso considerando los matices de aquellos dos conceptos, la idea de interfaz cultural resulta más clara para definir las dinámicas de ese espacio de contacto donde se desarrollaron transvases, contaminaciones y transmisiones recíprocas en las primeras interacciones entre conquistadores e indígenas. Más allá de los recorridos específicos de la etnografía y la antropología, que a su vez, se basan en el corpus colonial para iniciar sus registros (Levi-Strauss 1992, Clastres; Meliá y Candela) el estudio lingüístico-discursivo de los textos coloniales tiene mucho que aportar por ser éstos los primeros testimonios de esa experiencia de interfaz. Estos son los primeros documentos que declararon una realidad dinámica de una zona de contacto que es, sin duda, menos monolítica de lo que se podría imaginar. La interfaz indígena-colonial opera para entender diferentes fenómenos: uno de ellos es la constitución de las mitologías de los pueblos originarios tal como se difunden y se conoce hasta hoy. En este trabajo me centraré específicamente en la reelaboración discursivo/ literaria de este mito, dando centralidad a las fuentes y testimonios en su construcción narrativa.

En el caso de los mitos tupí-guaraníes, existe un amplio trabajo de lingüistas, etnólogos y antropólogos que ha hecho grandes aportes a la disciplina desde el siglo pasado $^{1}$. Estas contribuciones, además de ampliar el corpus de los siglos XVII-XIX, también hacen visibles la apropiación, sedimentación y resignificación de la lengua y las tradiciones orales tupi guaraníes por aquella cultura occidental escrita, cuyas implicancias de dominación ya han sido desarrolladas largamente por la historia de la lengua y la glotopolítica (Asencio; Errington 2002, 2008; Heller).

Más allá de las distinciones académicas, muchas leyendas de la cultura guaraní, por ejemplo, comparten el estatus de mito a nivel popular y escolar, pero poseen núcleos

\footnotetext{
${ }^{1}$ Pienso sobre todo en los trabajos de Nimuendaju, Metraux, Clastres, Meliá, Combes y Chamorro, Boidin, Candela y Melia para comenzar, y en una extensa lista que se sigue ampliando hasta el día de hoy. Estos trabajos confluyen con nuevas ediciones de manuscritos o reediciones críticas de textos que apuntan a configurar un mapa cada vez más representativo. Un ejemplo de referencia es el proyecto LANGAS, un portal en el que se dispone de documentos sobre lenguas generales de América Latina, patrocinado por el CNRS francés y dirigido por Capucine Boidin y Graciela Chamorro, entre otros. Ver: http://www.langas.cnrs.fr/\#/description
} 
narrativos que provienen de tradiciones escritas occidentales. Así como la leyenda apapocúva-guaraní de La tierra Sin Mal se engarza en el profetismo (Clastres; Cadogan; Villar/ Combés), y se ha retroalimentado y resignificado en diversos contextos, también hay otras leyendas de las que, si quisiéramos recuperar su raíz, su originalidad o si quisiéramos diferenciar en ellos los elementos nativos y los exógenos, comprobaríamos que es una ilusión inconducente ${ }^{2}$. Lo que cabe señalar aquí es entender la leyenda como espacio de interacción pero también como un constructo discursivo: una leyenda o relato mitíco ${ }^{3}$ es, desde su estructura, trama, densidad léxica y discursiva, siempre un objeto escriturario permeado por la contaminación, la traducción y el avatar es de cualquier archivo (DidiHuberman), incluso en aquellos trabajos de campo. Esto sucede básicamente porque en las transmisiones orales la materia misma de lo narrado implica la inestabilidad del contenido y a veces, de las formas, en comparación con la transmisión en las culturas escritas, porque éstas están basadas en características de la memoria verbal (Ong 43-71).

La leyenda como género literario es una modalidad narrativa muy vinculada con la transmisión oral y la tradición popular "caracterizada por su mundo ficticio anclado en lo fantástico y lo maravilloso pero normalmente con coordenadas espacio-temporales precisas" (Valles Calatrava 428); también, se trata de una transfiguración hiperbólica de un suceso real, y durante el romanticismo, en el mundo occidental tuvo su momento de

\footnotetext{
${ }^{2}$ Agradezco al Dr. Diego Villar y a la Dra. Capucine Boidinsus valiosos intercambios para pensar las bases de este trabajo.

La pervivencia de las leyendas indígenas, cuyo recorrido de transmisión se omite y del que casi nunca se reflexiona, se manifiesta en los diseños curriculares del Ministerio de Educación argentino, en donde se refleja que es un género "literario" con el que se trabaja en casi todos los grados de la escuela primaria (ver, por ejemplo, los diseños de los ministerios de la ciudad y la provincia de Buenos Aires: https://www.buenosaires.gob.ar/areas/educacion/curricula/pdf/dep1.pdf http://servicios.abc.gov.ar/lainstitucion/organismos/consejogeneral/disenioscurriculares/primaria/2018/discurricular-PBA-completo.pdf.

La leyenda como género letrado tuvo su cultivo desde los primeros años del país independiente, desde Juan María Gutiérrez y sus leyendas en verso hasta las leyendas argentinas de Rafael Obligado y las de Juan B. Ambrosetti, por mencionar sólo dos momentos representativos de este discurso dentro de la cultura letrada, pero luego permanecieron con insistencia en las prácticas escolares y populares. En todos estos casos no hay una reflexión sobre la práctica de la componenda de leyendas. Se admiten con indistinción que el origen de las leyendas son orales y con la ilusión de que su transmisión ha estado exenta de variaciones y contaminaciones, poniendo en entredicho cierta valoración crítica.

${ }^{3}$ Sigo, en cuanto a la conceptualización de "relato mítico", los trabajos de Eliade y Durand.

${ }^{4}$ Sobre narración oral, cuento y escritura en el ámbito hispano e indígena, ver los trabajos de Taylor, Montoya, Montemayor, Heyer y el clásico trabajo de Vansina.
} 
revitalización y revaloración, manteniendo siempre el carácter fantástico (428). Herederas de estas últimas modalidades narrativas, los primeros escritores nacionales o más tarde, los primeros folcloristas de Argentina, Uruguay y Paraguay adoptaron las formas románticas de la leyenda de cara a una recreación lírica, musical o autóctona de ciertos insumos de tradición indígena, y especialmente, en cuanto a los estudios de la cultura guaraní, también mediante las prescripciones del género romántico, se elaboraron las primeras mitografías, tomadas de la tradición oral y de ciertas fuentes escritas no declaradas, más cercanas a la libre interpretación de las formas que a un trabajo riguroso ${ }^{5}$. Esta corriente se vincula, desde luego, con los estudios sobre el cuento popular o folclórico que tiene un desarrollo muy notable durante el siglo XIX y XX, especialmente, en relación con los trabajos de lingüistas y académicos del folclore, en una tradición que se remonta a las investigaciones de Jacob y Wilhem Grimm y, más tarde, en Propp y Aarne, que ha sido desarrollado también en Argentina y en el mundo hispánico ${ }^{6}$.

Pero las leyendas como piezas literarias se consideran hoy en día como primeros aportes de los folkloristas quienes, a su vez, no dejaron huellas de los trabajos de campo o las fuentes o recolecciones, sino que, fieles a las formas orales y a su discontinua transmisión, elaboraron piezas de alta difusión y cuestionable entramado metodológico según parámetros de las disciplinas científicas.

\section{El relato de Tupí y Guaraní: fuentes y reelaboraciones}

Dentro de este grupo de folkloristas o mitógrafos de los guaraníes, se suelen destacar los trabajos de León Cadogan y GiralaYampey: con su firma se conocen distintos trabajos de recolección y antologías de mitos guaraníes, entre estos, aparece el relato de Tupí y Guaraní. Para hablar de esta historia que apunta a la explicación del origen, población y distribución de lenguas en una amplia zona de América del Sur, hay que considerar varias

\footnotetext{
${ }^{5}$ En Uruguay y Argentina los primeros románticos asumieron el formato de la leyenda para relatar historias sobre el pasado indígena, a partir de la circulación de los relatos coloniales. Pero además, Juan Bautista Ambrosetti, Rafael Obligado, Joaquín V. González, en Argentina, y Lauro Ayestarán en Uruguay, dieron cuenta, entre finales del siglo XIX y comienzos de siglo XX, de una materia cuya posibilidad literaria, cultural y musical comenzó a resignificarse y a plantearse como valor patrimonial.

${ }^{6}$ Ver Olrik, Thompson, Uther y Dégh como referencias internacionales del área. A partir de los trabajos de Menéndez Pidal, en el área de la literatura oral hispánica, se ha desarrollado largamente esta área en Argentina con los trabajos de Chertudi y Palleiro, además de Vidal de Battini, Cortázar y Latour de Botas, como ha sido comentado.
} 
cuestiones previas. Si quisiéramos optar por definir esta leyenda desde categorías ya perimidas, aunque no por eso aún funcionales en ciertos discursos, podríamos decir que la leyenda de los hermanos Tupí y Guaraní es un "mito apócrifo". Esto es porque no está incluido en todos los repertorios más rigurosos del tema, pero tiene su presencia en varios trabajos antológicos. En muchas ocasiones, las versiones populares de la mitología tupíguaraní suelen mezclar el mito de los hermanos Tupí y Guaraní con el ciclo cosmológico de los gemelos (Tremendore y Aricute) del cual hay un amplio registro en diversas culturas, tal como propone Levi Strauss en Historia de Lince. Sin embargo, el relato no tiene relación con el ciclo de los gemelos en la cultura tupínambá o ge, ya que estos mitos y sus variantes son siempre cosmogónicos y responden, con diferentes nombres, al origen de los jaguares y a los mitos sobre el sol y la luna (Levi-Strauss 1992, 23-91).

En el contexto de la mitografía y el relato de leyendas contemporáneas, León Cadogan relata en la introducción de su Literatura de los guaraníes de 1965 esta versión:

Una vieja leyenda habla de la existencia de dos hermanos, Tupí y Guaraní, que llegaron a la selva brasileña procedentes de una tierra misteriosa del otro lado del mar. Fundaron en su nuevo hogar la toldería y sembraron la tierra. Ahí vivieron en paz por algún tiempo, hasta que las disputas entre sus esposas hicieron imposible que los dos hermanos continuasen juntos. El mayor de ellos, Tupí, quedó en la región del Mato Grosso. Guaraní emigró hacia el sur y fundó la nueva raza que se extendió por el actual Paraguay.

En esta forma explica el propio guaraní su parentesco con el tupí, manifiesta indudablemente en la afinidad de los dos pueblos que abarcan la amplia zona selvática de América del Sur. Ambas ramas lingüísticas, tupí guaraní y karaivé-guaraní, caracterizan a gran cantidad de pueblos (...) La afinidad de ambos troncos, y aun de sus divisiones, es predominantemente lingüística. La lengua constituía el puente de contacto entre las islas habitadas en los claros de la selva.(...) Lo que la lengua unía era separado por la selva y por el orgullo de cada uno de los grupos (Cadogan s/p).

Cadogan explica, así, el origen de la raza y la lengua, incorporando allí también un carácter ético al comportamiento de los hermanos y los pueblos que engendraron ${ }^{7}$. Esta

\footnotetext{
${ }^{7}$ Rubén Bareiro, por su parte, en la Literatura guaraní del Paraguay, publicada por Biblioteca de Ayacucho en 1984, no menciona este relato, aunque cita a Cadogan como referencia. En cambio, relata el mito de los gemelos y el origen de los jaguares.
} 
misma variación de la leyenda la registra el folclorista Girala Yampey en Mitos y leyendas guaraníes quien dice que ambos hermanos eran hijos de un jefe de los Kari'o:

Aconteció en épocas muy remotas. Un numeroso grupo de Kari'o migró desde el Amazonas hacia el sur. Sus miembros, ocuparon las espléndidas cordilleras de tierras rojas del Guaira. El feraz suelo daba sustento generoso a los nuevos pobladores que se multiplicaron con rapidez. Un día, la mujer del mburuvicha principal dio a luz a un par de mellizos. Parecían los Gemelos míticos engendrados por Nandesy. Eran sanos, vigorosos e inteligentes. Se querían entrañablemente y juntos andaban de correría en correrías. Teniendo el mismo idioma avañe'ê y las mismas creencias, tradiciones y costumbres, no tenían motivos para disputar.

Jóvenes aún, eligieron esposas y formaron sus hogares uno al lado del otro. A la muerte del padre, los miembros de la tribu eligieron Mburuvicha a ambos, para que gobernaran por turno, uno cada cambio de luna. Todo marchaba sin dificultades. Eran verdaderos Kü'imba'e (dueños de su lengua), respetuosos y solidarios, el uno con el otro. Pero, un día, las esposas disputaron por la posesión de un loro grande y hablador. Como eran Kü'aña (lengua de aña), armaron tal riña que fue imposible reconciliarlas. A raíz de la desavenencia de sus mujeres, los hermanos comprendieron que la tribu había crecido tanto que resultaba imposible seguir todos juntos. Se separarían en dos grupos, expandiéndose por territorios diferentes. Decidieron que uno de los grupos emigraría hacia el Oeste y el otro al Este.

Así, dividido el tronco inicial, se formaron dos ramas denominadas: Guaraní, los del Oeste y Tupi, los del Este. Poco a poco, al diseminarse por las diversas regiones, en ambos grupos se formaron nuevas parcialidades que recibieron distintas denominaciones, siendo todos del común tronco kari'o (Yampey s/n).

La versión de Yampey está dentro del apartado "leyendas", creando así una distinción en su antología entre los mitos y éstas, una decisión significativa aunque carezca de explicación en su trabajo. En su versión, aparece el carácter secesionista de las comunidades a partir de la discordia entre sus mujeres por un papagayo, y la condición de hermanos gemelos, recuperando el carácter cosmogónico que Bareiro resume en la historia 
de Pa'i Rete Kuaray, y Jachyrá citando a Levy-Strauss, Nimuendajú y Samaniego (63) ${ }^{8}$.

Buscando los registros de la leyenda antes de la recuperación de Cadogan, muchas veces este mito aparece confundido con el de los gemelos, pero claramente la historia de los hermanos -uno mayor y otro el menor- que poblaron la tierra desde Las Antillas hasta la cuenca del Plata puede encontrarse en varios testimonios coloniales. Un ejemplo es la Historia do Brasil (1627) de Vicente Salvador, en cuyo capítulo XII se desarrolla el origen de las gentes y lenguas del Brasil, y se basa en una fuente española anterior para sostenerlo aunque, al referirla, lo ponga en duda:

D. Diogo de Avalos vizinho de Chuquiabue no Perunasua Miscelânea Austral, diz que nasserras de Altamira, em Espanha, havia uma gente bárbara, que tinha ordinária guerra com os espanhóis, e que comiam carne humana, do que enfadados os espanhóis juntaram suas forças, e lhes deram batalhan a Andaluzia, em que os desbarataram, e mataram muitos. Os poucos que ficaram não se podendo sustentar emterra a desempararam, e se embarcaram para onde a fortuna os guiasse, e assimderam consigo nas ilhas Fortunadas, que agora se chamam Canárias: tocaram as de Cabo Verde e aportaram no Brasil: saíram dois irmãos por cabos desta gente, um chamado Tupi e outro Guarani, este último deixando o Tupi povoando o Brasil passou ao Paraguai com sua gente, e povoou o Peru: esta opinião não é certa, e menos o são outras, que não refiro, porque não tem fundamento: o certo é que esta gente veio de outra parte, porém donde não se sabe, porque nem entre eles há escrituras, nem houve algum autor antigo, que deles escrevesse. O que de presente vemos é que todos são de cor castanha, e sem barba, e só se distinguem em ser emuns mais bárbaros, que outros /

\footnotetext{
${ }^{8}$ Esta historia, tomada de Cadogan, se incorporó en las antologías escolares de leyendas guaraníes, con una continuidad fluctuante, por ejemplo, en los textos escolares de la Editorial del Quirquincho reeditada por AZ (Palermo), y la antología Gente Americana: Los guaraníes, de AZ. Lucía Gálvezen su De la tierra sin mal al Paraíso, también recoge el relato: "Eran los tupí-guaraníes, los descendientes de aquellos míticos hermanos Tupí y Guaraní que, según la leyenda, habían llegado a la selva desde una tierra misteriosa situada al otro lado del mar. Enemistados entre ellos a causa de sus mujeres, se separaron conservando idioma y costumbres. Tupí, el mayor, quedó en la extensa región que va del Mato Grosso hasta el litoral atlántico cultivando la mandioca, en tanto Guaraní, cruzando el Paranapanema, proseguía hacia el sur y hacia el oeste, donde haría florecer las espigas del maíz" (1). En diversos blogs también hay referencias a esta leyenda como mito de población de la tierra por los guaraníes (por ejemplo, Vera Cabrera). Hay que tener en cuenta, sin duda, la diferencia entre leyenda y cuento popular, aunque sus dos formas de oralidad tengan dinámicas y espacios comunes. Dentro de los estudios folclóricos académicos cabe señalar la extensa labor de Berta Vidal de Battini, Augusto Raúl Cortázar y Olga Latour de Bottas quienes, a su vez, fueron figuras muy significativas en el diseño de textos escolares de lengua y literatura en la Argentina del siglo XX. Sus trabajos fueron pioneros en cuanto a la recolección de leyendas o cuentos populares, a veces atribuidos a etnias y otras veces, recogidas en trabajos de campo en distintas localidades argentinas.
} 
posto que todos o são assaz. Os mais bárbaros se chamam in genere. Tapuias, dos quaishá muitas castas de diversos nomes, diversas línguas, e inimigos uns dos outros (24).

El cuestionamiento de Salvador, a partir de la falta de escritura y autoridad que lo sostenga, más allá de la fuente citada de Diego Dávalos, es llamativa porque en la Miscelanea Austral no hay registro de este relato. Sin embargo, esa vinculación entre los hermanos Tupí y Guaraní y su origen en las sierras de Altamira es recogido por Martín del Barco Centenera en su poema épico Argentina y conquista del Río de la Plata (1602). En su obra, el arcediano dice que la fuente de la leyenda es Medina y sostiene que los tupiguaraní se originaron en una tierra vecina a Trujillo, en Extremadura, España, de donde, por otro lado, provenía él mismo (Barco Centenera). Allí habitaban unos caribes que hacían a sus antepasados "grande guerra". De entre ellos, dos hermanos llamados Tupi y Guaranì se fueron de la península en barcos, pero también andando ya que había partes del océano que entonces eran tierra firme. Así arribaron a las costas del Brasil. Según su relato, los dos eran hombres fuertes e inteligentes, jugaban y se divertían juntos y no había motivo de disputa entre ellos. Cuando muere su padre, la tribu los elige a los dos como jefes para que gobernaran por turno, hasta que una de sus mujeres codició el papagayo de la mujer del otro y se produjo un enfrentamiento entre los dos que originó la separación del pueblo. El grupo de guaraní se fue al sur y el de tupí, al norte. La historia de Centenera, además, remonta el origen de los caribes tupis a Túbal, el nieto de Noe que pobló España, empleando una solución de similitud filológica:

Aquéste fue el primero que en España pobló; pero después viniendo gentes con la de aqueste Túbal y otra extraña más, del mesmo Noé remanecientes, España se pobló, y tanta saña creció entre unos hombres muy valientes, Tupís, que por costumbre muy tirana, omaron a comer de carne humana.

Creciendo en multitud por esta tierra, Extremadura bella, aquesta gente de tan bestial designio y suerte perra por atajar tal mal de incontinente, hicieron los ricinos grande guerra 
contra aquestos caribes fuertemente; en tiempo que no estaba edificada

la torre de Mambrós tan afamada. (Barco Centenera, canto II, vv. 60-85).

El pueblo de Tupí, en España era caribe, es decir, comían carne humana, y cuando fueron expulsados por los ricinos, llegan a América, sucede la disputa por el papagayo. El traslado de los pueblos desde Europa hacia América se produce en un tiempo mítico a través de tierra firme, afirmación que el yo épico basa en el relato de Platón sobre la Atlántida. Este relato de los hermanos Tupì y Guaranì tiene una nota al margen del canto en el que menciona como fuente El libro de las grandezas y cosas memorables de España, de Pedro de Medina, a quien atribuye la historia cita en su capítulo 34. En la verificación de esta fuente, tampoco se comprueba referencia alguna sobre estos hermanos, pero si sobre la antigua composición de los continentes y los mares ${ }^{9}$.

Las matrices narrativas del relato tienen mucha cercanía con la explicación de la división de la tierra a partir de dos pueblos conducidos por dos hermanos que se encuentra en la Biblia, en varias ocasiones -la discordia y el destierro de Caín (Gen, 4), la dispersión de los descendientes de Noé (Gen, 10) y la separación de Abraham y Lot por disputas entre sus pastores, relato en el que el primero le dice al segundo: “¿No tienes todo el país por delante? Pues bien, apártate de mi lado. Si tomas por la izquierda, yo iré por la derecha; y si tú por la derecha, yo iré por la izquierda" (Gen 13, 8), Esaú y Jacob-, entre numerosos ejemplos. Pero también este motivo narrativo está presente en la tragedia Los siete contra Tebas, de Eurípides, y en el poema épico La Tebaida de Estacio, las que recuperan los episodios de los hermanos enfrentados y la alternancia en el poder de Eteocles y Polinices. La discordia entre hermanos y la distribución de la tierra implica, además, una explicación etiológica que no hay que perder de vista: Tupí de un lado, Guaraní del otro, es una suerte de racionalización histórico-antropológica, al decir de Villar (2017, s/p), y es también un constructo que responde al tema de hermanos enfrentados que atraviesan diversas mitologías y que revelan constantes en los mitos y relatos de las dinámicas del parentesco (Levi-Strauss 1981; Durand).

\footnotetext{
${ }^{9}$ Tampoco aparece la leyenda en las narraciones sobre la Francia Antártica en Cosmographie Universelle de Thevet (1575), en la que narra historias vinculadas con los tupíes, por ejemplo, la lucha entre las tribus Margageaz y Tabajares (944-953).
} 
La cita espuria de Diego Dávalos que hace Salvador y la adjudicada a Medina por parte de Barco Centenera configuran un procedimiento de atribuciones erróneas y entrecruzadas que, de todos modos, era una práctica escritural habitual en su contexto. En esto, pues, se presenta el punto en donde comienza a operar como funcional el concepto de interfaz indígena-colonial: ¿hasta dónde esta historia es una invención de Barco Centenera o del primer cronista que lo relatara?, ¿hasta dónde es una leyenda guaraní?, ¿hasta qué punto la leyenda se genera como constructo literario a partir del contacto con los españoles? Estas preguntas, por válidas que sean, se producen a partir de una ilusión de certeza que responde a prácticas disciplinarias establecidas pero que están articuladas, al decir de Gruzinski, en torno a una reflexión que trata menos de penetrar en los mundos indígenas para hallar en ellos una "autenticidad" conservada de milagro o perdida sin remedio, que evaluar tres siglos de un proceso de occidentalización, en sus manifestaciones menos espectaculares, pero también más insidiosas. Última opción ésta que responde, hay que aceptado, tanto a la orientación deliberada de nuestra problemática como a limitaciones inherentes a las fuentes (11).

Ese proceso de occidentalización, como parte de la dinámica de la interfaz indígenacolonial, es un aspecto indiscutible que hay integrar en el análisis de las fuentes coloniales y en los discursos mitográficos. Tanto los trabajos de campo de especialistas como los relatos compilados de folcloristas o escritores, muestran evidencias de un proceso que permiten seguir el hilo de la incorporación de un relato a los discursos atribuibles a comunidades no-tipográficas. Este proceso complejo, en el que se debe tomar distancia de fuentes y avatares de transmisión es, por demás, necesario integrar para entender que muchas de las explicaciones son funcionales a la elaboración, contexto y pervivencia de los relatos.

\section{Etiología y política de la leyenda}

Después de este breve recorrido de la inclusión de la leyenda en textos de diversa clase y época, es importante centrarse en uno de los aspectos más significativo del caso, es decir, la fundamentación providencialista que está, en mi opinión, en el origen de la etiología (y de la política) de la leyenda. El problema del origen de los pobladores americanos fue un asunto de fuerte debate cuando se tomó conciencia de la llegada a un 
continente nuevo. En línea con el habitual recurso histórico tardomedieval y renacentista la explicación sobre el origen de los pobladores americanos se buscó en la Biblia. Gonzalo Fernández de Oviedo es el primer historiador americano que en 1553 ofrece dos alternativas en relación al origen de los habitantes americanos: o bien eran provenientes de Cartago o eran de antiguos pueblos españoles (i-iv); de esta manera, se inaugura en el discurso colonial la instauración del origen transatlántico de los pueblos americanos.

Mientras que Bartolomé de las Casas sostiene que el origen del hombre americano estaba en Asia (ya que las indias occidentales estarían conectadas con las orientales) (Castiglione 261), López de Gómara, en el otro polo de su consideración antropológica, también menciona que el origen debe remontarse a la Atlántida (314), hipótesis que sostienen varios autores españoles y europeos del momento ${ }^{10}$. Uno de los argumentos de López de Gómara para sostener esto fue el de la filiación genética de ciertos fonemas náhuatl, explicación proto-filológica para fundar evidencias de la continuidad de las tierras que unían el viejo continente con América:

Platón cuenta, en los diálogos Timeo y Critias, que hubo antiquísimamente en el mar Atlántico y Océano grandes tierras y una isla dicha Atlántide, mayor que África y Asia, afirmando ser aquellas tierras de allí verdaderamente firmes y grandes, y que los reyes de aquella isla señorearon mucha parte de África y de Europa. Empero que con un gran terremoto y lluvia se hundió la isla, sorbiendo los hombres, y quedó tanto cieno, que no se pudo navegar más aquel mar Atlántico. Algunos tienen esto por fábula, y muchos por historia verdadera; y Próculo, según Marsilio dice, alega ciertas historias de los de Etiopía, que hizo un Marcelo, donde se confirma. Pero no hay para qué disputar ni dudar de la isla Atlántide, pues el descubrimiento y conquistas de las Indias aclaran llanamente lo que Platón escribió de aquellas tierras, y en México llaman a el agua atl, vocablo que parece, ya que no sea, al de la isla (López de Gómara 313-314).

Por su parte, Benito Arias Montano, en su mapamundi de la Biblia Poliglota Complutense, explicaba que los descendientes de Noé poblaron el Nuevo Mundo: Ophis

\footnotetext{
${ }^{10}$ Antonio Castiglione menciona, además de las fuentes aquí presentadas, a otros autores que también mencionan el origen transatlántico de la población de América: Agustín de Zárate y su Historia del descubrimiento y conquista de la provincia del Perú (1555), Francisco Cervantes de Salazar y la Crónica de Nueva España (1566) y a Pedro Sarmiento de Gamboa y su Historia de los Incas (1572).
} 
llegó al Perú y Jobal colonizó el Brasil (Castiglione 266-269). El, como otros, sostenían que el origen americano se narraba en el capítulo 13 del libro 4 del apócrifo Esdras. De ahí sostienen que los habitantes de América descienden de los marinos judíos que el rey Salomón envió a Ophir (Ofir). Ophir, según la Biblia, era un lejano país rico en oro, piedras preciosas y maderas olorosas (Acosta 28). Este linaje judío de los habitantes de América, parte de la tradición libresca colonial, fue, de todos modos, refutado pocos años después por José de Acosta (26-31).

El dato de autoridad de Aristóteles también lo recoge Centenera, pero sólo como condición geográfica necesaria para traslado de un punto a otro. Barco Centenera se centra sobre todo en una cuestión política, un tema que jalona diversos puntos de vista de su poema épico. Al explicar el origen en Extremadura de los tupí-guaraníes, y por lo tanto, de los chiriguanos (pueblos descendientes, según él, de los hermanos enfrentados) explica también la relación de este pueblo con los Pizarros en Perú y su beligerancia en la zona de Santa Cruz de la Sierra:

Muy trillada cosa es que el descubrimiento del Perú, y lo que los Pizarros hicieron, dicen, pues, que el corazón pedía la venganza, id est, que los chiriguanos, movidos de mal distinto, como que adivinando que los Pizarros eran procreados en aquella tierra Extremadura, de adonde sus antepasados habían sido echados, se alegraban para hacer el trueco que entre ellos, dice, "en matando a quien mató cosa mía", pero fue tanta la fama de los Pizarros entre los Indios que aun los chiriguanos, sin experimentar su valor, les temieron, y así cesaron por aquel tiempo de su conquista, y pararon en las cordilleras de Chuquisaca, de donde hoy, primero de octubre de 1592, aun hace daño y matan los que van a Santa Cruz de la Sierra (nota 9, canto I).

El arcediano, en esta oportunidad, al igual que cuando establece la denostación moral de los jefes de las expediciones al Río de la Plata, Juan Ortiz de Zárate, Pedro de Mendoza y Diego de Mendieta, introduce el comentario de los Pizarro pero según la dialéctica política-regional española que domina su discurso. Él, como extremeño, reivindica a su pueblo como los señores naturales (pobladores ancestrales) y, por tanto, los dueños legítimos de esas nuevas tierras conquistadas, y demarca a los vascos y otros pueblos españoles como los pretendidos e inmorales adelantados de esas expediciones. La explicación del origen de los tupí-guaraníes en Extremadura cobra un sentido irreversible, 
en una atribución de legimitación basada en el relato mítico, en un pasado absoluto que no hace más que justificar sus aspiraciones políticas. Pero, a su vez, reviste fuertes connotaciones providencialistas: la atribución de que los indígenas americanos son también descendientes "genuinos" de Noé, habilita, según la concepción teológica de la época de reconocible base aristotélico-tomista, que cada ser humano del mundo tenía que poder conocer el evangelio, tenía que estar incluido en el llamado "plan de salvación cristiano" (Iglesia Católica 763). Desde Bartolomé de las Casas hasta José de Acosta, la integración teológica y bíblica de los nativos americanos al plan divino fue el salvoconducto para considerar el aparato catequético de la conquista.

\section{Conclusión: la dialéctica del malentendido}

Así, es probable que sea el poema épico de Barco Centenera el primer relato en español donde se mencione la leyenda de los dos hermanos Tupí y Guaraní. Tal vez esta incorporación de la historia al poema épico tenga su origen en relatos orales de los guaraníes que el arcediano haya recibido de forma directa o referida, y se vincula claramente con los mitos en los que hermanos y gemelos están en el origen cosmogónico de este pueblo indígena. De todas maneras, este discurso, en el poema épico como en las otras fuentes coloniales, tiene una organización narrativa muy cercana a relatos clásicos y bíblicos que forman parte de la tradición occidental, aunque hoy se divulgue como parte de la mitografía guaraní en leyendas folclóricas y en textos escolares.

Tanto las fuentes coloniales como los relatos folclóricos implican una creación cultural que es propia y ajena a la vez, a cada individuo y a cada grupo: "modos y técnicas de expresión, recuerdos, percepciones del tiempo y del espacio, imaginarios, brindan así materia para explorar los intercambios de adopciones, la asimilación y la deformación de los rasgos europeos, las dialécticas del malentendido, de la apropiación y la enajenación" (Gruzinski 10). Esa “dialéctica del malentendido" es, por otro lado, lo que opera en un nivel contextual en cada relato: ya sea como evidencia de una concepción teológica en la que el indio americano, como cualquier pagano del mundo conocido, debía ser incluido en la propagación de la fe, ya sea como un relato que explica la enorme extensión territorial de los tupí-guaraníes y su consistente cercanía lingüística y cultural, cuestión que tematizan los relatos folclóricos. 
En suma, la consideración de cada relato en su contexto, de cada transmisión y transmutación en la interfaz indígena-colonial, da cuenta de diversas dimensiones espaciales: la traslación, contaminación, pérdida y trasmutación que esta implica desdeña los conceptos de lo apócrifo y lo original, deja de lado la ilusión de lo auténtico o propiamente indígena. En el caso del guaraní, cuya lengua y cultura no contaron con registros mnemotécnicos ni pictóricos conocidos antes de la llegada del europeo, es inviable definir fuente o base documental de origen. En las múltiples reelaboraciones de mitos y leyendas, a medio camino entre lo etnológico, lo folclórico y lo literario, operan significaciones y mutaciones de lo oral y lo textual. Así, cuando se establecieron dinámicas de intercambio en aquellas zonas de contacto, ya nada permaneció igual y lo que se sigue ejecutando son negociaciones y apropiaciones, a partir de las cuales no se conocen los extremos, más allá de las técnicas etnográficas y antropológicas que puedan distinguir la pervivencia o la fuerza de un segmento exclusivamente atribuible a determinada identidad. La interfaz implica migración y desplazamiento, pero también, apropiación de formulaciones que sólo los testimonios escritos permiten analizar como resultados netos, en los que no siempre pueden evidenciarse matrices distinguibles.

\section{Bibliografîa}

Aarne, Antti y Thompson, Stith. The types of the folk tale: a Classification and Bibliography. Helsinki: Academia Scientiarum Fennica, 1928.

Acosta de, Josef. Historia natural y moral de las Indias. Ed. Fermín del Pino Díaz. Madrid: Consejo Superior de Investigaciones Científicas, 2008.

Asencio, Eugenio. "La lengua compañera del imperio. Historia de una idea de Nebrija en España y Portugal.” Revista de Filología Española, 43, 3/4 (1960): 390-413.

Barco Centenera del, Martín. Argentina y conquista del Río de la Plata. Ed. Silvia Tieffemberg. Buenos Aires, Argentina: Eudeba, 1998.

Bareiro, Rubén. Literatura guaraní del Paraguay. Caracas, Venezuela: Biblioteca de Ayacucho, 1984.

Boidin, Capucine. 'Jopara o Jehe'a?, mestizaje de las plantas, de los cuerpos y de las lenguas en Paraguay". Acción 206 (2000): 28-31.

Boone, Elizabeth. y Mignolo, Walter. Writing without Words. Durham-London: Duke University, 1994.

Cadogan, León. Ayvu Rapyta: textos míticos de los Mbyá-Guaraní del Guairá. Asunción, Paraguay: Biblioteca Paraguaya de Antropología, 1992.

Candela, Guillaume y Bartolomeu Melia. "Lenguas y pueblos tupí-guaraníes en las fuentes de los siglos XVI y XVII.” Mélanges de la Casa de Velázquez 45-1 (2015): 57-76. 
Castiglioni, Antonio Virgilio. "Los judíos en América antes de Colón. Acerca del poblamiento de América y de Argentina." Revista de la Junta de Estudios Históricos de Tucumán 14 (2014): 257-277.

Castro Klarén, Sara. The narrow pass of our nerves: writing, coloniality, and postcolonial theory. Madrid, Frankfurt: Iberoamericana, Vervuert, 2011.

Iglesia Católica. Catecismo de la iglesia católica. Vaticano: Librería Editrice Vaticana, 2012.

Chertudi, Susana. El cuento folklórico. Buenos Aires, Argentina: OMEP, 1978.

Clastres, Hélène. La terre sans mal. Le prophétisme tupi-guarani. París: Seuil, 1975.

Combes, Isabelle y Chamorro, Graciela. Povos indígenas em Mato Grosso do Sul. História, cultura e transformações sociais. Dourados, MS: UFGD, 2015.

De Toro, Alfonso. Ed. Postmodernidad y postcolonialidad. Breves reflexiones. Leipzig: Universitätaus Leipzig-Vervuert Verlag, 1997.

De Toro, Alfonso y De Toro, Fernando. El debate de la postcolonialidad en Latinoamérica. Una postmodernidad periférica o cambio de paradigma en el pensamiento latinoamericano. Madrid: Iberoamericana, 1999.

Dégh, Linda y Vázsonyi, Andrew. "Legend and belief." Folklore Genres. Ed. Dan BenAmos. Austin: University of Texas Press, 1976. 93-123.

Didi-Huberman, Georges. "El archivo arde." Las lenguas del archivo. Eds. Graciela Goldchluk, y Juan Antonio Ennis. La Plata, Argentina: Colectivo crítico, 2019. (En prensa).

Durand, Gilbert. Las estructuras antropológicas del imaginario. México: Fondo de Cultura Económica, 2004.

Eliade, Mircea. Mito y realidad. Barcelona: Kairós, 1999.

Errington, Joseph. "Colonial Linguistics.” Annual Review of Anthropology, 30 (2001): 1939.

Errington, Joseph. Linguistics in a colonial world. A story of languaje. Oxford- Malden MA: Blackwell, 2003.

Gálvez, Lucía. De la tierra sin mal al paraíso. Guaraníes y jesuitas. Buenos Aires, Argentina: Aguilar, 2013.

Garibay, Ângel M. Panorama literario de los pueblos nahuas. México: Porrúa, 1963

Gruzinski, Serge. La colonización de lo imaginario. Sociedades indígenas y occidentalización en el México español. Siglo XVI-XVIII. México: Fondo de Cultura Económica, 2016.

Heller, Monica y McElhinny, Bonnie. Language, capitalism, colonialism. Toronto: University of Toronto Press, 2018.

Heyer, Richard Haly. The true, the false, and the sacred: making sense in mesoamerican oral traditions. México: UMI Disertation Services, 1992.

La Biblia de Jerusalén. Bilbao: Desclée de Brouwer, 1998.

León Portilla, Miguel. La visión de los vencidos. México: Universidad Nacional Autónoma de México, 1951.

Lévi-Strauss, Claude. Historia de lince. Barcelona: Anagrama, 1992.

Lévi-Strauss, Claude. Las estructuras elementales del parentesco. Buenos Aires, Argentina: Planeta, 1981.

Lienhard, Martin. "Of mestizajes, heterogeneities, hybridisms and other chimeras: onthe macro processes of cultural interaction in Latin America". Journal of Latin 
American Cultural Studies 6. 2 (1997): 183-200.

López de Gómara, Francisco. Historia general de las Indias. Zaragoza, 1521.

Meliá, Bartomeu. "La tierra sin mal de los Guaraní: economía y profecía.”. Chiriguano. Ed. Jürgen Riester Santa Cruz: APCOB, (1993). 291-319.

Menéndez Pidal, Ramón. "Estudios sobre el Romancero". Obras Completas. Ramón, Menéndez Pidal, Madrid: Espasa Calpe, 1974.

Métraux, Alfred. La religion des tupinamba et ses rapports avec celle des autres tribus tupi-guarani. Paris: E. Leroux, 1928.

Mignolo, Walter. "Epistemic disobedience and the decolonial option: a manifesto."Transmodernity Journal of Peripheral Cultural Production of the Luso Hispanic World, 201(2010): 44-66.

Mignolo, Walter. The darker side of the renaissance. Ann Arbor: University of Michigan, 1995.

Montemayor, Carlos. El cuento indígena de tradición oral: notas sobre sus fuentes y clasificaciones. Oaxaca: Instituto Oaxaqueño de las Culturas (IOC), 1996.

Montoya, Víctor. La tradición oral latinoamericana. 7 de 22 de 2016. http://www.cuatrogatos.org/docs/articulos/articulos_189.pdf.

Nakata, Martin. The cultural interface: an exploration of the intersection of western knowledge systems and torres strait islanders positions and experiences. Tesis doctoral. Syndey: James Cook University, 1997.

Nimuendaju-Unkel, Curt. Los mitos de creación y de destrucción del mundo como fundamentos de la religión de los Apapokuva-Guaraní. Lima: Centro Amazónico de Antropología y Aplicación Práctica, 1978.

Oesterreicher, Wulf. "Estudio introductorio". La conquista del Perú. Pedro Barragán.Madrid-Frankfurt: Iberoamericana-Vervuert, 2011. 11-58.

Olrik, Axel. Principles for oral narrative research. Bloomington: Indiana University Press, 1992.

Ong, Walter. Oralidad y escritura. Tecnologías de la palabra. México: Fondo de Cultura Económica, 2006.

Ortiz, Fernando. Contrapunteo cubano del tabaco y del azúcar. Madrid: Cátedra, 2002.

Palermo, Miguel Ángel. Los guaraníes. Buenos Aires, Argentina: AZ, 2015.

Palleiro, María Inés. "Cuento folklórico y narrativa oral: versiones, variantes y estudios de génesis". Cuadernos Lirico, 9 (2013). https://journals.openedition.org/lirico/1120.

Pratt, Mary Louis. "Arts of the contact zone". Profession 33(1992): 33-40.

Propp, Vladimir. Morfología del cuento. Buenos Aires, Argentina: Juan Goyanarte, 1972.

Taylor, Gerald. La tradición oral andina y la escritura. Lima: Luis, 1988.

Thevet, André. Cosmographie universelle. Paris: Chez Michel Sonnius, 1575.

Thompson, Stith. The folk tale. New York: The Dryen Press, 1946.

Valles Calatrava, José R Ed. Diccionario de teoría de la narrativa. Granada: Alhulia, 2002. Vansina, Jan. La tradición oral. Madrid: Labor, 1966.

Vera Cabrera, Víctor. Tupí y guaraní. Génesis de una raza. (s.f.) http://lio.tripod.com/tupigua.htm

Vidal de Battini, Berta. Cuentos y leyendas populares de la Argentina. Buenos Aires, Argentina: Ediciones culturales argentinas, 1983.

Villar, Diego. Consulta mitología tupí guaraní. Buenos Aires, Argentina, enero de 2017.

Villar, Diego y Combés, Isabelle. "La tierra sin mal. Leyenda de la creación y destrucción 
de un mito." Tellus 24.13 (2013): 201-225.

Watchel, Nathan. La vision des vaincus - Les indiens du pérou devant la conquêtespagnole. (1530-1570). Paris: Gallimard, 1971.

Yampey, Girala. Mitos y leyendas guaraníes, 2003. https://www.portalguarani.com/627_girala_yampey.html. 